\title{
A COUNTEREXAMPLE TO A COMPACT EMBEDDING THEOREM FOR FUNCTIONS WITH VALUES IN A HILBERT SPACE
}

\author{
Accepted for publication to the \\ Proceedings of the American Mathematical Society \\ Providence, RI USA \\ S. MIGÓRSKI \\ Jagellonian University, Institute for Information Sciences \\ ul. Nawojki 11, 30072 Cracow, Poland \\ E-mail: migorski@softlab.ii.uj.edu.pl \\ Fax: 4812 341865
}

Let $V$ and $H$ be two real separable Hilbert spaces with $V$ densely and continuously embedded in $H$. Identifying $H$ with its dual, we have a Gelfand triple $\left(V, H, V^{\prime}\right)$, where $V^{\prime}$ is the dual space to $V$. For a positive $T$, let $\mathscr{Q}=L^{2}(0, T ; V), q^{\prime}=L^{2}\left(0, T ; V^{\prime}\right)$ denote the spaces of the square summable functions defined on $(0, T)$ with values in $V$ and $V^{\prime}$, respectively. Let us define $\mathscr{W}=\left\{v \in \mathscr{V}: v^{\prime} \in \mathscr{V}^{\prime}\right\}$, where the time derivative $u^{\prime}=\frac{d u}{d t}$ is understood in the weak sense. Equipped with the standard norm $\|v\|_{w}=\left(\|v\|_{q}^{2}+\left\|v^{\prime}\right\|_{q^{\prime}}^{2}\right)^{\frac{1}{2}}, w_{\text {becomes a Hilbert space. It is }}$ known (cf. [2]) that the embedding

$$
\mathscr{W} \subset C(0, T ; H)
$$

is continuous, where the space of continuous functions from $[0, T]$ into $H$, is endowed with the supremum norm. E. Nagy proved the following theorem in [3].

Theorem: If $V$ and $H$ are infinite-dimensional separable Hilbert spaces such that $V \subset H$ densely, continuously and compactly, then embedding (1) is also compact.

The purpose of the paper is to deliver that this result of Nagy was recently exploited in several papers in connection with the study of evolution equations and inclusions (see, for instance, [1]).

\section{References}

[1] Hu, S., Lakshmikantham, V. and Papageorgiou, N.S., On the solution set of nonlinear evolution inclusions, Dynamic Systems Appl. 1 (1992), 71-82.

[2] Lions, J.L. and Magenes, E., Problémes aux limites non homogénes et applications, vol. 1, Dunod, Paris 1968.

[3] Nagy, E.V., A theorem on compact embedding for functions with values in an infinite dimensional Hilbert space, Ann. Univ. Sci. Budapest Eötvös Sect. Math. 22-23 (1979-80), 243-245. 


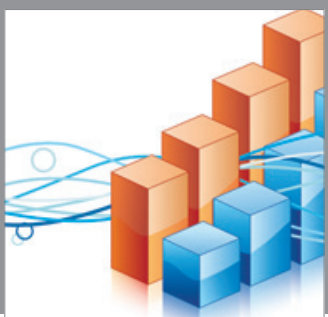

Advances in

Operations Research

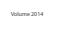

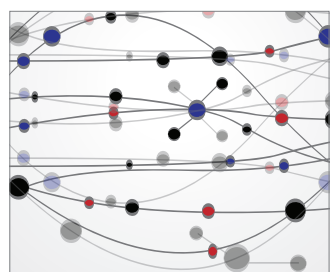

\section{The Scientific} World Journal
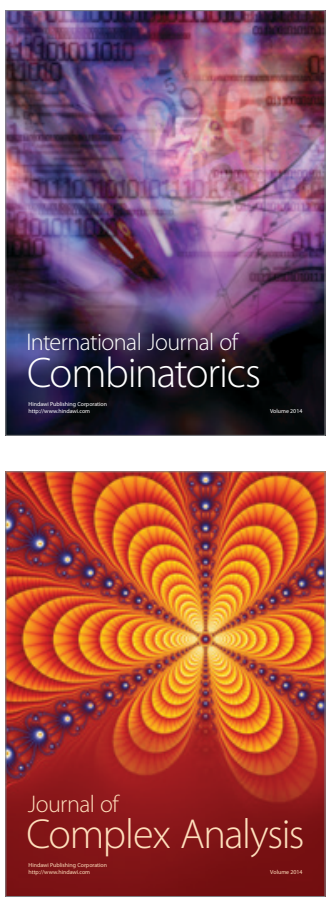

International Journal of

Mathematics and

Mathematical

Sciences
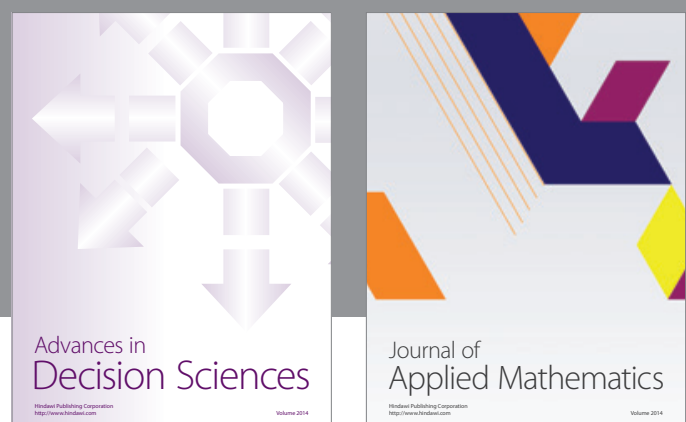

Journal of

Applied Mathematics
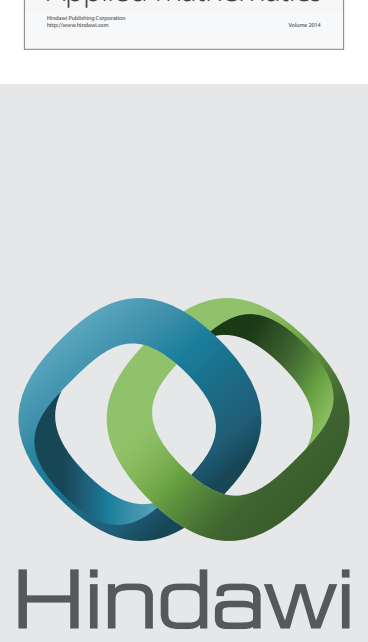

Submit your manuscripts at http://www.hindawi.com
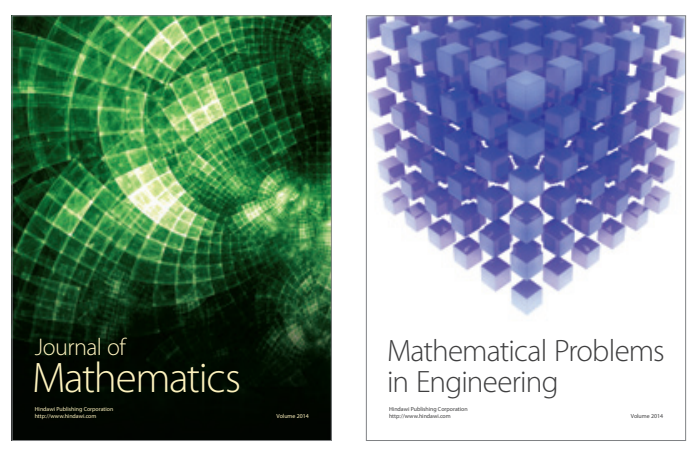

Mathematical Problems in Engineering
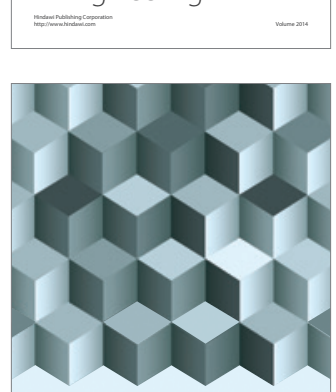

Journal of

Function Spaces
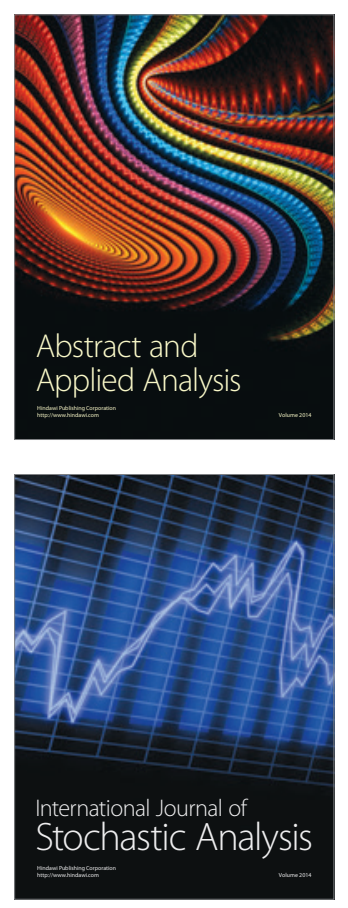

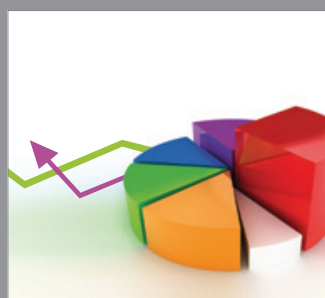

ournal of

Probability and Statistics

Promensencen
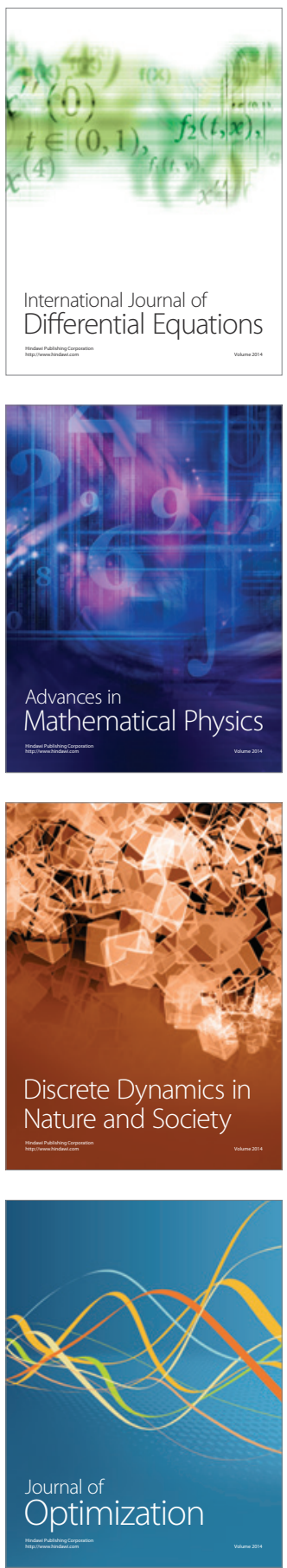